\title{
INTRODUCTION TO THE ISSUE
}

Every time socially oriented legislation is passed, it symbolizes the hopes and dreams of some segment of the American people. Even now, four years after President Bush signed it into law, the Americans with Disabilities Act (ADA) generates hope and, for some, fear. Imbedded in the ADA is a key that will literally and figuratively unlock doors to access and inclusion. Behind those symbolic doors stand those who, because of stigma, misunderstanding, and fear, have been unwilling to enrich their community and work lives with those who have disabilities. The time is right, but overdue, because people with disabilities represent the last minority in this country to have their oppression acknowledged.

The ADA has spawned a new industry of "ADA awareness." Scores of publications, manuals, training sessions, and discussions about the law and its potential have taken place around the country. We have heard the rhetoric. Now it is time for the results. Surprisingly, documentation of the extent and effectiveness of implementation has been scarce. In this special issue of the Journal of Vocational Rehabilitation, a group of distinguished authors, each representing different stakeholders, provide analyses or perspectives on implementation of the ADA. Collectively, this work gives us a map that tracks our progress from 1990 and provides some guideposts for the future. Much of these data describe positive outcomes for people with disabilities and give hope for future implementation efforts. The issue is structured into four sections as described below.

\section{CONSUMER PERSPECTIVE}

Rick Douglas performs many roles as Executive Director of the President's Committee for Employment of People with Disabilities. One of them is challenging those who support the ADA to work harder for its use. In his article, Douglas discusses the accomplishments of the past few years, most notably in training and public awareness, that have helped to awaken the consciousness of business. Douglas outlines several critical areas for action: health care reform, advocacy, increased information distribution, enforcement, and compliance.

Advocacy efforts and the importance of selfdetermination are echoed by Ed Turner. As a disability rights advocate for the past 12 years, Turner has repeatedly experienced discrimination. His message, aimed primarily at people with disabilities, says that to truly benefit from the ADA, people with disabilities must become totally familiar with all aspects of the law. He speaks about the powerful effects the law can have on consumers' lives. Turner also cautions that ADA will continue to be only a promise unless people with disabilities are familiar with its regulations, receive training in use of the law to uphold their civil rights, and take leadership roles in implementation.

\section{BUSINESS RESPONSE}

Businesses' attitudes toward ADA are frequently portrayed negatively in the media. Most often, we hear about numbers of claims and expensive and laborious legal procedures. Many businesses have taken a proactive, problem-solving approach to accommodation and accessibility. Their responses are explained in four articles in this section. John Kregel and Yoshikazu Tomiyasu report on their research study on business attitudes. Their results relate to employer knowledge of ADA, employers' experiences and contacts with people with disabilities, and factors that affect attitudes. This analysis reveals that employers recognize the contributions people with disabilities make to their workplaces. An interesting finding is the large amount of contact employers had with individuals with disabilities in their personal lives.

The Job Accommodation Network (JAN) has recently concluded an analysis of its customers to determine accommodation issues and impact, costs associated with accommodation, recipients of service, and types of jobs involved. These data report that both employers and employees still require basic ADA information, three years after Title I. Although people with disabilities continue to file claims with the Equal Employment Opportunity Commission, their use of JAN is surpassed 
by employers. Hendricks et al. recommend that people with disabilities advocate more strongly when involved in an employment search and use the resources available to them.

The Business Accommodation Response Team (BART) is a pilot project developed to offer a quick, prescriptive response to business and employer problems. Flippo and Green describe case studies of several individuals who received BART assistance. A characteristic of this project is extensive employer input and evaluation.

Rehabilitation professionals often speculate about what business thinks about ADA. Not all employers have taken a "sour grapes" approach to compliance. Barry Curtis and Dennis Campbell, two employers from very different companies, speak about ADA from their perspectives. Their opinions corroborate research showing that businesses need more information and local resources to help them understand and comply with ADA.

\section{ASSISTIVE TECHNOLOGY}

The "Tech Act," a predecessor of the ADA, embraces many of the values found in the later Act. Many people both in and outside of human services are unaware of assistive technology services and devices. Button and Wobschall define assistive technology services and devices and give many examples of how to use technology to make accommodations.

Students with disabilities represent part of our future labor force. Behrmann and Schepis exam- ine and analyze assessment protocols given to five students in the transition process to determine their assistive technology requirements. A new assessment approach, video screening, is presented. This approach enables rehabilitation engineers to evaluate the individual's needs in natural environments.

\section{EMPIRICAL OBSERVATION}

Peter Blanck has been involved in researching the ADA since its passage. In his article, Blanck reports on an empirical study of 3,000 individuals. This study assesses the effect the ADA has had on their employment, integration, and economic opportunity. Blanck also identifies emerging issues for vocational rehabilitation personnel regarding the ADA.

These authors have given us insights into how the ADA is perceived. More important are the approaches they have identified that make the ADA work, and the challenges they have presented. Future analysis of the law must continue to focus on the critical stakeholders represented here: people with disabilities, employers, and the community as a whole. Above all, the momentum that guided the passage of the ADA should be sustained and channeled into action if we are to experience full compliance. As Thomas Paine said, "those who expect to reap the blessings of freedom must . . . undergo the fatigue of supporting it."

Karen F. Flippo, MRA 